\title{
A propósito de emancipação em Christophe Dejours
}

Christophe Dejours. Trabalho vivo: trabalho $e$ emancipação. Brasília, Paralelo 15, 2012, 2 vols. 436 páginas.

Sadi Dal Rosso

Christophe Dejours é amplamente conhecido por suas críticas às teses neoliberais que defendem princípios e práticas de organização do trabalho, cujas consequências para os trabalhadores são conhecidas na sociologia, antropologia, psicologia, gestão do trabalho e economia. É significativa sua contribuição para o estudo das relações entre subjetividade e trabalho e grande estimulador da psicodinâmica do trabalho. Em 2012, a editora Paralelo 15, de Brasília, publicou Trabalho vivo: trabalho e emancipação, livro organizado em dois volumes: o primeiro, sobre sexualidade e trabalho; o segundo, a respeito de trabalho e emancipação.

As 436 páginas da obra atestam a grandiosidade do empreendimento intelectual do autor, que visa não só relacionar sexualidade e trabalho, mas também desenvolver uma ousada proposta de emancipação. Do ponto de vista metodológico, seus fundamentos ancoram-se em debates teóricos sobre o sentido do trabalho para a realização ou desgraça humanas, disponíveis na ampla literatura das ciências sociais e da psicanálise e em conhecimentos práticos decorrentes da longa experiência adquirida em práticas clínicas.

O livro investiga que relações existem e podem ser desenvolvidas entre a centralidade da sexualidade e a centralidade do trabalho. A centralidade da sexualidade para o ser humano é desenvolvida com base em conceitos e teses de Freud e de outros autores. Já a centralidade do trabalho, como é tratada no livro, resulta de uma elaboração própria do autor, que combina, de maneira muito particular, as relações entre afeto e trabalho. Os pesquisadores das ciências sociais sabem que essa questão começou a colocar-se para os conhecimentos do trabalho a partir do advento da modernidade, quando questôes magnas - tais como construir teoricamente uma explicação para os fundamentos do valor no trabalho - tornaram-se necessárias e o trabalho 
passou a desempenhar papel insubstituível para a acumulação de capital.

A empreitada de Dejours inicia-se pelos fundamentos do trabalho para o sujeito. O sentido ontológico da questão ultrapassa o âmbito da proposta - amplamente acatada pelo autor, aliás - de que o trabalho transforma o ser social. Dejours defende que o corpo também produz conhecimentos, o que implica a distinção entre trabalho prescrito e trabalho real. O conhecimento para a realização do trabalho real é produzido pela inteligência do corpo, não pela inteligência reflexa. $\mathrm{O}$ autor separa, pois, as inteligências aplicadas ao trabalho em inteligência reflexa e inteligência do corpo. A inteligência do corpo tem fundamentos tão profundos no âmago do ser humano quanto a sexualidade. O trabalho é uma dimensão importante para o sujeito não apenas na vida adulta, quando sai à procura de emprego, mas desde as fases iniciais da infância. Por meio da inteligência do corpo, o sujeito, aqui representado pela criança, ainda não dispondo do respaldo do aparato inteiramente desenvolvido da inteligência reflexiva, enfrenta as provas que o mundo real apresenta e, a seu modo, propóe diálogos e desafios aos adultos, assimila respostas, introjeta comportamentos, hábitos e práticas. Essa inteligência do corpo, que pode ser detectada por mecanismos semelhantes aos que movem a sexualidade, continua com o sujeito em todas as fases de sua vida, sendo responsável pela geração dos conhecimentos aplicados à resolução de problemas suscitados pelo trabalho real no dia a dia. Ela mobiliza toda a parte afetiva do sujeito, inclusive os sonhos, que são uma peça importante na explicitação de problemas e na procura de soluções.

Esse modo de apropriação do real pelo corpo é chamado de corpropriação. "Este corpo se apropria do mundo [...] [e é a] corpropriação do mundo". Este é o segundo corpo; não é o corpo dos biólogos. "Ao segundo corpo, a este corpo subjetivo [...] dá-se na psicanálise o nome de corpo erógeno. Pois possuímos dois corpos" - o corpo biológico e o corpo erógeno. $\mathrm{O}$ corpo erógeno é construído aos poucos "na relação corpo a corpo entre a criança e o adulto em torno dos cuidados e asseios corporais [...] os cuidados com o corpo estão contaminados pelo sexual e é essa contaminação sexual que está na origem da excitação e das curiosidades da criança que, por seu turno, estão na origem de seu corpo erótico e de sua sexualidade. E é bem este mesmo corpo da experiência a mais íntima e da relação com o outro, que é convocado no trabalhar" (vol. I, p. 30).

Nesse campo do pré-reflexo encontram-se no sujeito trabalho e sexualidade.

A proposta, que chamei de ontológica, sobre a compreensão da natureza do sujeito é uma questão maior para a filosofia, para a psicologia e para as demais esferas do conhecimento que têm na complexidade do ser humano seus temas de investigação. Não admira, pois, que o autor recorra aos gregos para resgatar argumentos em favor de sua interpretação, passando por autores modernos, como Freud, da psicanálise e a da psicodinâmica do trabalho.

A proposta de Dejours é impecável analítica e teoricamente: sexualidade e trabalho encontram-se nos espaços da inteligência astuciosa do corpo, no espaço do pré-reflexo, espaço real que move o trabalho e que é responsável por partes significativas do trabalho. Sexualidade e trabalho não são antagônicos. A inteligência reflexa deve uma grande quantidade de elementos à experiência do corpo, por meio do qual se desenvolvem conhecimentos e experiências que ficam anexados ao pensamento reflexo. A teoria freudiana não desenvolveu uma construção para o lugar do corpo no sujeito, como fez em relação à sexualidade. Esse empreendimento é reflexivamente assumido pelo autor, valendo acrescentar que se trata de um projeto com caráter emancipatório para o sujeito mediante o trabalho, "um projeto fundador de uma antropologia do trabalho" (vol. I, p. 87).

Como seria a relação do corpo com a produção do pensamento imaterial? Como nasce uma ideia a partir da experiência do corpo? Como o pensamento e o Eu se engendram a partir do corpo biológico? A tese construída segue Freud, para quem a parte mais importante não estaria no consciente, no reflexivo, nos atos controlados pela inteligência formal do sujeito, mas no arcano, no escondido, reprimido no subconsciente. O pensamento nasce com a cooperação do corpo, é desenvolvido pelo corpo, passa pelo corpo, implica o corpo, não se restringe apenas à mente reflexiva 
e estruturante. Daí que o "Eu é um Eu-corpo. O Eu é um corpo pensante” (vol. I, p. 81). Dejours trata as instâncias como duas inteligências, ou como dois corpos e não como uma inteligência e um corpo que se desdobram em mais de uma forma de manifestação, uma exterior e interior. $\mathrm{O}$ exemplo da criança recém-nascida e sua expressão da vontade por meio do choro e de outras manifestações corporais ilustra aquilo que o autor estabelece como a percepção imediata. A criança expressa pelo choro sua vontade, e suas reações respondem ao meio ambiente. É como se o corpo falasse de uma forma diversa que os demais apreendem intuitivamente. A inteligência do corpo é uma inteligência astuciosa. $\mathrm{O}$ terreno da apreensão por meio da reflexividade seria algo distinto, pois a inteligência da mente supõe a mobilização de faculdades e operaçôes distintas.

No caminho de construir uma teoria do trabalho que incorpore a subjetividade, o autor de alguma maneira segue a trajetória de Freud, de acordo com a qual forças importantes encontram-se sitiadas no inconsciente e sua explicitação pode incidir na construção do bem ou do mal para o sujeito em si e para as demais pessoas envolvidas. Assim operaria também a subjetividade em relação ao trabalho, ao desencadear forças que podem ser construtivas ou destrutivas, portadoras de prazer ou sofrimento, de realização ou recalque, que cooperam para o desenvolvimento ou escravização e que fariam parte do ser humano.

Os comentários feitos até aqui são insuficientes para dar conta da discussão extremamente elaborada do autor nos oito capítulos que compóem o primeiro volume. Dejours trata da questão da inteligência do corpo, desenvolve os fundamentos filosóficos da teoria do corpo pensante, avança no sentido de uma teoria da centralidade da sexualidade, compatível com uma teoria da centralidade do trabalho, abre espaço para a questão da gênese da violência, interpreta a violência ordinária no trabalho doméstico e retoma, por fim, a tese da "corpropriação do mundo". Ele realiza uma façanha ao articular o sujeito que trabalha com a sexualidade que lhe é inerente, a qual é impossível deixar fora do contexto. Essa maneira de conceber o indivíduo que trabalha em seus aspectos integrais tem um sentido holista. Quem tra- balha não é só uma cabeça pensante, uma mão operante ou um sentimento ambulante. A pessoa que trabalha é una, integral, cabeça, mão e sentimento. É impossível ao trabalhador deixar de fora de seu local de trabalho uma paixão reprimida, um problema financeiro mal resolvido, a dor na mão arranhada, no joelho ou no pé torcido.

O segundo volume da obra retém a mesma estrutura do primeiro. São oito capítulos - o que atesta a impossibilidade de um balanço das principais ideias - nos quais o autor desenvolve a tese da emancipação pelo trabalho. Se emancipação não é um conceito novo nos estudos do trabalho, são novas a forma de tratamento e a proposta política de implementação do projeto emancipatório que ele formula.

Dejours se defende da crítica de que sua teoria do trabalho seria individualizante, introduzindo a dimensão de sexo e gênero, pela qual capta o vigoroso movimento das mulheres, e incluindo noções tais quais cooperação e democracia como parte do projeto emancipatório do trabalho. "O trabalhar envolve a relação subjetiva com a tarefa, que pertence ao campo individual, e a cooperação, que pertence ao campo coletivo" (vol. II, p. 189). "É possível reunir a subjetividade singular e a ação coletiva na pólis" (vol. II, p. 42) numa proposta política maior, que incorpora também a dimensão de autonomia no trabalho. Desse aspecto surge a crítica ao neoliberalismo e a suas práticas de individualização e de concorrência, de avaliações quantitativa e objetiva do trabalho e de remuneração segundo essas avaliações. Esse conjunto produziria impactos negativos sobre a saúde física e mental dos trabalhadores, entre os quais são mencionados o agravamento das patologias mentais, novas patologias, suicídios, patologias de intensificação do trabalho, patologias de assédio e outros componentes negativos do trabalho contemporâneo.

A que condiçôes deveria atender uma política do trabalho e como ela poderia ser organizada para modificar uma sociedade calcada em circuitos que produzem negatividades? A base para tal proposta consiste na "compreensão da força colossal do trabalho em relação a solidariedades, civilidade, cultura, direito e instituiçôes" (vol. II, p. 204), para o bem ou para o mal. Do reconhecimento 
dessa força imensa podem derivar princípios para uma política transformadora do trabalho. Seria necessário: a) desenvolver uma "doutrina do trabalho com base na reavaliação das relações entre trabalho e pólis, trabalho e violência, trabalho e escola, trabalho e cultura, trabalho e democracia" (Idem); b) fazer evoluir os métodos de direção e gerenciamento de empresas e órgãos púbicos; c) formar pesquisadores e professores "de forma a remanejar os conteúdos do ensino em grandes escolas destinadas à formação de engenheiros, administradores, economistas" (Idem); d) "introduzir o ensino dos princípios de uma política do trabalho nas universidades e demais instituições de ensino superior" (Idem); e) "operar uma verdadeira mutação, apoiada por um debate de dimensôes nacionais" (vol. II, p. 205).

Como avaliar uma proposta dessa natureza? O próprio autor registra um realismo cético. "Um remanejamento tão considerável parece hoje bem pouco provável. Mas então a decadência de nossa cultura e de nossa sociedade não poderá ser controlada" (Idem). Ante a força do neoliberalismo na sociedade mundial, não poderia ser outra a avaliação de que a "conjuntura não está propícia para a plena recuperação das políticas de trabalho. É antes tempo para controvérsia [...] meditação" (Idem). Como poderia ser explicitada uma crítica a esse de outra maneira imponente - projeto intelectual? Por indigitação de ausências, de vazios e respectivas implicações, que apontariam para a incompletude da proposta teórica e de intervenção.

Não encontram guarida no esquema conceitual do autor movimentos sociais, associações, sindicatos, partidos e classes. Exceto o movimento das mulheres, outras dimensões da "ação coletiva" estão ausentes do livro. Elas não têm um papel significativo a desempenhar e podem ser substituídas por um "debate nacional". Na proposta de transformação há espaço somente para representantes institucionais, como pesquisadores e professores, e não para organizaçôes de luta social, como sindicatos, associações, movimentos, classes e partidos.

Outra ausência notória na concepção geral do mundo do trabalho tem a ver com a organização capitalista contemporânea do trabalho, que visa a acumulação de capital pela maneira mais racional possível. A gestão do trabalho não é a mesma através do tempo. São notórias as diferenças entre as formas taylorista, fordista e toyotista, que vêm se sucedendo e que representam esforços concentrados de pesquisadores e consultores a fim de incrementar a produtividade do trabalho a benefício das empresas. Vale mencionar que, em sua concepção de organização, trabalhadores e empregadores não são relacionados de forma contraditória, contrária, divergente; têm interesses e práticas diversos, mas não opostos - cada trabalhador tem que saber como os outros trabalham, e é necessário que confiem tanto nos "colegas como nos chefes" (vol. II, p. 80). É possível assim desenvolver ações conjuntas de transformação estrutural entre empregadores e trabalhadores, uma vez que os móveis das açôes encontram-se nas bases de constituição do ser humano e podem ser modificados, acompanhando a transformação dos indivíduos em clínicas de trabalho, bem como a massificação e a generalização dessa "doutrina do trabalho" em universidades e instituições de ensino superior e em debates nacionais. Porém, se existir uma relação conflitiva entre empregadores e trabalhadores, a mutação dos indivíduos também releva uma transformação social maior, que põe em xeque os princípios estruturadores da acumulação. Talvez o fundamento real da crítica alçada a Marx (vol. II, p. 75) pela alienação do trabalho seja de outra natureza, correspondendo à compreensão do social-real como cooperativo e não conflitivo.

Como conseguir autonomia e emancipação no trabalho quando a propriedade dos meios e dos instrumentos é privada? A propriedade privada conduz à concentração da riqueza e ao emprego de estratégias de gestão que continuamente elevem a produtividade e intensidade do trabalho. A autonomia e a emancipação requerem que o controle sobre as condições de exercício do trabalho estejam nas mãos dos trabalhadores. Para que o trabalho exerça um papel virtuoso que contribua com o desenvolvimento dos seres humanos, estes devem manter em suas mãos o controle das condições sociais. Como dominar novas formas de intensificação do trabalho se o controle do emprego está subordinado aos donos dos negócios, que com eles visam aumentar seus ganhos? 
O leitor atento poderá enunciar outros pontos críticos, ausentes da obra de Christophe Dejours. Entretanto, as ciências sociais têm diversas razões para justificar uma leitura cuidadosa do texto: porque ele constrói uma proposta sobre trabalho com objetivo emancipatório; porque critica o neoliberalismo em sua forma política de flexibilização de direitos; porque defende a tese da centralidade do trabalho perante aqueles que acham que o trabalho acabou ou está por acabar, quando, diariamente, quase 3 bilhões de pessoas trabalham oito horas ao dia.

SADI DAL ROSSO

é professor titular do Departamento de Sociologia da Universidade de Brasília e pesquisador do CNPq. E-mail: sadi@unb.br. 